\title{
The case for statins: has it really been made?
}

\author{
Andrew Thompson $\mathrm{PhD}^{1} \quad$ Norman J Temple $\mathrm{PhD}^{2}$
}

J R Soc Med 2004;97:461-464

Statin drugs are a modern success story. They are the medical treatment for coronary disease and the star of the pharmaceutical industry. Worldwide, sales of statins are running at about $\$ 19$ billion a year and growing quickly. ${ }^{1}$ This success profits not only the pharmaceutical industry but also all those whose finances and careers are furthered by the research and the sales. But to what extent is it also a success for the general public? To answer this we will look at the major long-term (five to six year) clinical trials of statins. We start with the treatment offered to the participants, then look at the endpoints that were selected, and continue with a look at how the results have been reported. We conclude with a discussion of the costeffectiveness of statins for people at different levels of risk of coronary heart disease (CHD).

\section{THE COMPARISON GROUP: BEST CURRENT TREATMENT OR PLACEBO?}

The control groups in all of the trials have been given placebo pills. A more strenuous comparison, that of the 'best current prophylactic, diagnostic, and therapeutic methods,' was advocated by the World Medical Association in the Declaration of Helsinki. ${ }^{2}$ For statins, this is not another drug but lifestyle factors. The European Atherosclerosis Society 1987 guidelines made dietary management 'the sole therapy for the majority of people with elevated levels [of blood lipids]'. ${ }^{3}$ Furthermore, 'A dietitian, supported by the patient's physician, is best able to instruct the patient, adapt the diet to energy needs and food preferences, and [if the response is inadequate] to monitor ongoing compliance.' A year later the US National Cholesterol Education Program ${ }^{4}$ stated:

'Drug therapy is likely to continue for many years, or for a lifetime. Hence, the decision to add drug therapy to the regimen should be made only after vigorous efforts at dietary treatment have not proven sufficient.'

Vigorous efforts are defined as a minimum of six months of intensive dietary counselling before starting drug

${ }^{1}$ Riehen, Switzerland; ${ }^{2}$ Athabasca University, Athabasca, Alberta, Canada

Correspondence to: Norman J Temple PhD, Centre for Science, Athabasca University, Athabasca, Alberta T9S 3A3, Canada

E-mail: normant@athabascau.ca therapy. This is to occur in two steps. Step one involves a total fat intake of less than $30 \%$ of calories, less than $10 \%$ of which is saturated fat, and less than $300 \mathrm{mg}$ per day of cholesterol. If that does not bring the blood cholesterol down to the target level, then a step two diet is initiated which lowers the intake of saturated fat and cholesterol still further. 'Involvement of a dietitian is very useful, particularly for intensive dietary therapy such as the Step Two Diet.' 4

All of the trials were initiated after the publication of these guidelines. ${ }^{5-13}$ What the researchers did instead was to recommend a step one diet, wait a few weeks - not six months - and then, if the desired levels of blood cholesterol were not reached, enrol the patients into the study proper.

Why were these guidelines not followed? Certainly the initial cost would be greater, but from a public point of view it would seem advisable since a dietary regimen would not only help reduce CHD but could have a beneficial result on several other diseases and save on the costs of multiple procedures, not just statin drugs.

One thing that might have happened if all participants had been given dietary intervention before starting statins is that it would have much reduced the differences in deaths from CHD and all-cause mortality in the trials (see Table 1).

\section{THE PROBLEM OF ENDPOINTS}

A sign of a mature scientific strategy is consistency in the criteria that are used to measure its success. But one of the most inconsistent aspects of the statin trials is the choice and variety of endpoints. Some single-criterion items are found in some of the trials but not in others, and there is an evergrowing list of items that are placed in varying combination with each other. All-cause mortality, the only measure not prone to diagnostic variance, is not popular. It is not even reported in a sub-study of the Heart Protection Study (HPS $)^{13}$ and has to be searched for in several of the other trials.

Combination endpoints are often used - such as death, myocardial infarction (MI), and stroke - and only the first event is counted. Most of these combination endpoints are conceptually inconsistent. Some of the studies add in a treatment, usually a form of revascularization. Treatments are arbitrary physician-chosen entities, not instances of morbidity. Why this huge palette of combination events? Could it be that the study designers are searching for the combination that is most apt to yield a positive result and 


\begin{tabular}{|c|c|c|c|c|c|c|}
\hline \multirow[b]{2}{*}{ Trial } & \multirow[b]{2}{*}{ Type of trial } & \multirow[b]{2}{*}{ Patients } & \multicolumn{2}{|c|}{ All-cause mortality } & \multicolumn{2}{|c|}{ CHD mortality } \\
\hline & & & Abs \% & NNT & Abs \% & $N N T$ \\
\hline 4S (Ref 5) & Secondary & & 3.3 & 30 & 3.5 & 29 \\
\hline LIPID (Ref 6) & Secondary & & 3.1 & 32 & 1.9 & 53 \\
\hline CARE I (Ref 7) & Secondary & & $<1$ & $>100$ & 1.1 & 91 \\
\hline CARE ॥ (Ref 8) & Secondary & Age $65-75$ & \multicolumn{2}{|c|}{ not reported } & $<1$ & $\infty$ \\
\hline WOSCOPS (Ref 9) & Primary & & $<1$ & $>100$ & $<1$ & $>100$ \\
\hline ALLHAT-LLT (Ref 10) & Primary & Hypertension & $<1$ & $>100$ & 0.0 & $\infty$ \\
\hline AFCAPS/TexCAPS (Ref 11) & Primary & & $<1$ & $>100$ & $<1$ & $>100$ \\
\hline $\begin{array}{l}\text { Heart Protection Study (HPS) } \\
\text { (Ref 12) }\end{array}$ & $\begin{array}{l}\text { Mainly primary } \\
(14 \% \text { secondary })\end{array}$ & $35 \%$ with type 2 diabetes & 1.8 & 56 & 1.5 & 67 \\
\hline $\begin{array}{l}\text { Heart Protection Study (sub-study) } \\
\text { (Ref 13) }\end{array}$ & Mainly primary & Type 2 diabetes & 2.0 & 50 & 2.1 & $48^{\star}$ \\
\hline
\end{tabular}

${ }^{*}$ All vascular caused deaths

$\mathrm{CHD}=$ coronary heart disease; Abs \%=absolute difference in \%; NNT=number needed to treat

avoid those that probably will not? This would not be the scientific approach but would make sense if the aim was to make the study appear highly successful. A recent review of 167 trials suggests just such a possibility. ${ }^{14}$ It found that 'the inclusion of a clinician-driven outcome was predictive of a statistically significant result for the primary composite outcome.' In other words, the studies would not have yielded positive results if they had stuck to morbidity measures.

With respect to data on deaths the most important endpoint is all-cause mortality. This can be manipulated only by fraud and is the one of primary concern to the recipients of the treatment - are they less likely to die soon, whatever the reason, if they take this drug? Of course, a detailed breakdown of causes of death must also be included. For morbidity items, we need to have clear information on the patient's quality of life. If a drug or other intervention neither extends life nor improves its overall quality, then it is of no value. We need to focus on these two endpoints and they should be kept separate, not put together in piecemeal fashion. Regrettably, there is no rigorous reporting of all-cause morbidity, nor of measurement of changes in overall quality of life, in any of the studies. Rather, it is assumed that less CHD-related morbidity leads to less morbidity overall.

Unfortunately, designating all-cause mortality and overall quality of life as the primary endpoints is not 'usual practice' in the medical research world. Such a shift from a medical industry perspective to a public benefit perspective is long overdue. ${ }^{15,16}$

\section{PRESENTATION OF TRIAL DATA}

The statin trials found absolute differences of less than $1 \%$ control and treatment groups, and from $1.1 \%$ to $4.7 \%$ in the most standard combined event, fatal and nonfatal MI. These are not impressive results. But there is a way of making them look impressive - namely, by expressing the results as relative difference rather than as absolute difference. Take, for example, the LIPID trial. ${ }^{6}$ It involved only patients with $\mathrm{CHD}$ (i.e. it was a secondary prevention trial). The difference in deaths between the statin group and the placebo group was $3.1 \%$ (14.1\% of the placebo group died and $11 \%$ of the statin group). But the impact of these results can be much magnified by expressing them as relative differences: 'The statin drug lowered the risk of death by $22 \%$ ' (11 is $22 \%$ lower than 14.1 ).

Another serious problem with the way the results are presented is that the reader is often not told the number needed to treat (NNT) for one patient to benefit. The NNTs range from around 30 in the $4 \mathrm{~S}$ and LIPID trials to over 100 in the primary prevention trials. But this is not the information that patients are likely to be given; instead, they will be told that they will reduce their risk of death by about $30 \%$. Presenting information to patients in the form of relative risk will much increase their receptiveness to taking the drug.

$4 \mathrm{~S}$ and LIPID were secondary prevention trials in patients with CHD and high cholesterol. Because the participants were at high risk of death from CHD, the NNTs are modest. Many such patients, perhaps a majority, may therefore agree to take statins, even when given an unbiased version of the efficacy of the drug. But the situation is altogether different when we turn our attention to primary trials. Here, the participants have one or more risk factors for CHD and are therefore at increased risk for the disease. However, their risk of death from CHD is still much lower than that of participants in secondary trials. As 
indicated in the Table, the NNT for such patients is much higher, often well over 100. In these circumstances the way the 'facts' are presented is likely to have an enormous impact on whether the patient agrees to take statins. Does the doctor say: 'Mr Smith, if you take statins this will reduce your risk of dying from heart disease by $30 \%$ '? Or does she say: 'Mr Smith, if you take statins, then in seven years' time there is a one chance in about 120 that your death will have been prevented'? We argue that the latter is a much more honest version of the clinical reality.

\section{COST-EFFECTIVENESS OF STATINS}

Now let us look at the cost of preventing CHD by using statins. The simplest, minimum-assumption, calculation is based on three factors - the cost of the drug per year, the NNT, and the length of the trials. The two secondary prevention trials indicate an NNT of about 30 to postpone one death. ${ }^{5,6}$ Using this figure and a conservative estimate of the cost of the statin drugs per year of $\$ 500$, we arrive at the cost of postponing one death of $\$ 85500(500 \times 30 \times 5.7)$.

But that figure becomes much higher when we use data from the primary prevention trials, as the NNTs are much higher. This has become especially relevant because the latest NCEP III guidelines have considerably lowered the eligibility requirements for using statin drugs. ${ }^{17}$ This was done by lowering the LDL-C threshold from $\geqslant 4.1 \mathrm{mmol} / \mathrm{L}$ to $\geqslant 3.3 \mathrm{mmol} / \mathrm{L}$ in conjunction with various risk factors, some of which were also modified to be more inclusive. According to a detailed analysis it was estimated that the new guidelines have the effect of expanding the number of people in the USA who are now eligible for lipid lowering by drug therapy, which in most cases means statins, from 15 million to 36 million, a jump of $140 \%$ at a stroke. ${ }^{18}$ It is noteworthy that the chair of the committee that wrote these guidelines as well as five of the 13 members of the committee have received drug company funding. The European recommendations are very similar, with targets of $5 \mathrm{mmol} / \mathrm{L}$ for total cholesterol and $3 \mathrm{mmol} / \mathrm{L}$ for LDL.

The effect of widening the net for use of statins means that millions of people at only modest risk of CHD will be eligible. For such people the cost will be exceedingly high for the benefit achieved. We can illustrate this by looking at a recent estimate. Using data from the HPS trials, Marshall ${ }^{19}$ compared the relative cost-effectiveness of aspirin, hypertension treatment, and a statin. His calculations were based on costs in the UK and focused on patients at a $10 \%$ risk of experiencing a major coronary event in the next five years. He estimated that aspirin could prevent one CHD event (CHD death, angina, MI) for $£ 3500$, compared with $£ 61400$ for statins. Another important point made by Marshall was that, if patients at high risk of $\mathrm{CHD}$ are given aspirin, then the cost of preventing a coronary event by also giving statins becomes much higher than the above figure. This is because, since the risk of CHD has now been reduced by aspirin, the NNT for statins has increased, and the cost of preventing a CHD event with a statin has therefore also much increased. It is arguable that statins are cost-effective for the small minority of people at especially high risk of CHD. However, the case for statins becomes particularly dubious when we consider the impact of throwing the net wider to include, for example, people in their fifties whose only risk factor is a high cholesterol. In North America, the drug companies are advertising directly to that section of the population, urging them to ask their doctor for a prescription for statins. For people at that risk level, the cost of statins translates to more than $\$ 300000$ to prevent a major CHD event. In the UK National Health Service, statins are at present available only to people whose global risk is greater than $3 \%$ per year - a figure much influenced by the cost of the drugs and other pressures on the exchequer. In other European countries, clinicians have more latitude. This year the UK Government has tacitly acknowledged a wider demand by making one of the statins, simvastatin, available without prescription. Presumably the British public will in due course be exposed to a direct marketing campaign on North American lines. The diversion of incomes, whether personal or national, to such high-cost low-efficacy interventions is always something to be resisted. What is the opportunity cost of such expenditure? In national terms the NNT required to lift a young person out of poverty, thus resulting in better health and more productivity, is probably much superior.

\section{CONCLUSIONS}

The design of the trials has not involved the testing of the value of statin drugs relative to that of guidelinerecommended promotion of lifestyle changes. The small differences favouring the drug have been magnified by the manner of presentation of results, most notably by the use of relative differences between statins and placebo groups rather than absolute differences. A broad societal perspective is lacking with regard to acceptable costs of these and other medical interventions. Lowering the threshold to make much larger numbers of people eligible for drug therapy has the effect of making statins an extremely expensive means of preventing heart disease. The case for statin drugs, especially for primary prevention, has not been made.

\section{REFERENCES}

1 http://nf4.newsfutures.com/bk/market/grpIndex.html?_gid=14. Accessed 2 May, 2004 
2 Lewis JA, Jonsson B, Kreutz G, Sampaio C, van Zwieten-Boot B. Placebo-controlled trials and the Declaration of Helsinki. Lancet 2002;359:1337-40

3 European Atherosclerosis Society. Strategies for the prevention of coronary heart disease: a policy statement. Eur Heart J 1987;8:77-88

4 The Expert Panel. Report of the National Cholesterol Education Program Expert Panel on Detection, Evaluation, and Treatment of High Blood Cholesterol in Adults. Arch Intern Med 1988;148: $36-69$

5 Scandinavian Simvastatin Survival Study Group. Randomised trial of cholesterol lowering in 4444 patients with coronary heart disease: the Scandinavian Simvastatin Survival Study (4S). Lancet 1994;344:1383-9

6 The Long-Term Intervention with Pravastatin in Ischemic Disease (LIPID) Study Group. Prevention of cardiovascular events and death with pravastatin in patients with coronary heart disease and a broad range of initial cholesterol levels. N Engl J Med 1998;339:1349-57

7 Sacks FM, Pfeffer MA, Moye LA. The effect of pravastatin on coronary events after myocardial infarction in patients with average cholesterol levels. Cholesterol and Recurrent Events Trial investigators. N Engl J Med 1996;335:1001-9

8 Lewis SJ, Moye LA, Sacks FM, et al. Effect of pravastatin on cardiovascular events in older patients with myocardial infarction and cholesterol levels in the average range. Results of the Cholesterol and Recurrent Events (CARE) trial. Ann Intern Med 1998;129:681-9

9 Shepherd J, Gobbe SM, Ford I, et al. Prevention of coronary heart disease with pravastatin in men with hypercholesterolemia. West of Scotland Coronary Prevention Study Group. $N$ Engl J Med 1995;333:1301-7

10 ALLHAT Officers and Coordinators for the ALLHAT Collaborative Research Group. The Antihypertensive and Lipid-Lowering Treatment to Prevent Heart Attack Trial. Major outcomes in moderately hypercholesterolemic, hypertensive patients randomized in pravastatin vs usual care: The Antihypertensive and Lipid-Lowering Treatment to Prevent Heart Attack Trial (ALLHAT-LLT). JAMA 2002;288: 2998-3007
11 Downs JR, Clearfield M, Weis S, et al. Primary prevention of acute coronary events with lovastatin in men and women with average cholesterol levels: results of AFCAPS/TexCAPS. Air Force/ Texas Coronary Atherosclerosis Prevention Study. JAMA 1998; 279: $1615-22$

12 Heart Protection Study Collaborative Group. MRC/BHF Heart Protection Study of cholesterol lowering with simvastatin in 20536 high-risk individuals: a randomised placebo-controlled trial. Lancet 2002;360:7-22

13 Collins R, Armitage J, Parish S, Sleigh P, Peto R; Heart Protection Study Collaborative Group. MRC/BHF Heart Protection Study of cholesterol-lowering with simvastatin in 5963 people with diabetes: a randomised placebo-controlled trial. Lancet 2003;361:2005-16

14 Freemantle N, Calvert M, Wood J, Eastaugh J, Griffin C. Composite outcomes in randomized trials: greater precision but with greater uncertainty? JAMA 2003;289:2554-9

15 Thompson A, Temple N. Ethics, Medical Research, and Medicine. Dordrecht: Kluwer Academic Press, 2001

16 Thompson A, Temple N, eds. Ethics, Medical Research, and Medicine: Commercialism Versus Environmentalism and Social Justice. London: Kluwer Academic, 2001

17 National Cholesterol Education Program (NCEP) Expert Panel on Detection, Evaluation, and Treatment of High Blood Cholesterol in Adults (Adult Treatment Panel III). Third Report of the National Cholesterol Education Program (NCEP) Expert Panel on Detection, Evaluation, and Treatment of High Blood Cholesterol in Adults (Adult Treatment Panel III) final report. Circulation 2002; 106:3143-421

18 Fedder DO, Koro CE, L'Italien GJ. New National Cholesterol Education Program III guidelines for primary prevention lipidlowering drug therapy: projected impact on the size, sex, and age distribution of the treatment-eligible population. Circulation 2002; 105:152-6

19 Marshall T. Coronary heart disease prevention: insights from modelling incremental cost effectiveness. BMJ 2003;327:1264-7 